\title{
Walter Benjamin em Gotham City: sobre a violência pura ${ }^{1}$
}

\author{
Walter Benjamin in Gotham City: on pure violence
}

\section{Andityas Soares de Moura Costa Matos}

Universidade Federal de Minas Gerais, Belo Horizonte - MG, Brasil

\begin{abstract}
Resumo: O presente trabalho reflete brevemente sobre as ideias de violência pura e de estado de exceção efetivo no pensamento de Walter Benjamin (1892-1940), lançando na seção 2 a hipótese de que são resultados de uma longa meditação que começa com o texto Sobre a crítica da violência (1921), passa pelo denso fragmento $O$ caráter destrutivo (1931) e chega á obra intitulada Teses sobre o conceito de história (1940), quando Benjamin percebe com clareza à impossibilidade de se negociar com as instituições democrático-liberais, as quais funcionam como estruturas desaceleradoras (katéchonta) do tempo da revolução, leitura apresentada na seção 1 mediante a profanação do conceito original schmittiano. $\mathrm{O}$ artigo passa então na seção 3 a interpretar as ideias de Benjamin em um cenário de ficção - a trilogia Batman de Christopher Nolan - que a cada dia parece mais terrivelmente real, concluindo com um parágrafo de sabor agambeniano sobre o direito-que-vem (seção 4).
\end{abstract}

Palavras-chave: Walter Benjamin. Katéchon. Estado de Exceção. Violência Pura. Batman. Direito-que-vem.

\begin{abstract}
This paper briefly reflects on the ideas of pure violence and effective state of exception according to the thought of Walter Benjamin (1892-1940), proposing in section II the hypothesis that these concepts are the result of a deep reflection which begins with the essay Critique of violence (1921), goes through the dense fragment The destructive character (1931) and arrives at the Theses on the concept of history (1940), when Benjamin clearly realizes the impossibility of negotiating with the liberal-democratic institutions, which work as decelerator structures (katéchonta) of the coming time, reading that is presented in section I through the profanation of the original Schmitt's concept. Then the article in section III interprets Benjamin's ideas in a fictional scenario - the Batman trilogy by Christopher Nolan - which seems more terribly real every day, concluding with an agambenian paragraph about the coming law (section IV).
\end{abstract}

Keywords: Walter Benjamin. Katéchon. State of exception. Pure violence. Batman. Coming law.

${ }^{1}$ Este trabalho foi realizado durante meu estágio pós-doutoral na Facultat de Dret de la Universitat de Barcelona (Espanya), com bolsa da CAPES, Fundação à qual agradeço pela excelência e seriedade no trato com a pesquisa e a produção de novos conhecimentos.

Recebido em: 02/04/2016

Revisado em: 30/07/2016

Aprovado em: 07/08/2016 


\section{Katéchon}

O katéchon é uma figura escatológica paulina adotada por Carl Schmitt e que aparece na Segunda Epístola aos Tessalonicenses (2-12). Literalmente, pode-se traduzir o termo - um particípio grego neutro - como "aquele que atrasa" ou "aquele que detém", correspondendo, portanto, a um desacelerador do tempo da vinda do Messias ou, em chave teológico-política, da justiça divina (Benjamin), ou do "direito que vem" (Agamben). Na passagem bíblica original, Paulo relata a vinda do "ímpio", sendo o katéchon aquilo - ou aquele? - que detém a aparição do Anticristo:

Ninguém de maneira alguma vos engane; porque não será assim sem que antes venha a apostasia, e se manifeste o homem do pecado, o filho da perdição, o qual se opõe, e se levanta contra tudo o que se chama Deus, ou se adora; de sorte que se assentará, como Deus, no templo de Deus, querendo parecer Deus. Não vos lembrais de que estas coisas vos dizia quando ainda estava convosco? E agora vós sabeis o que o detém, para que a seu próprio tempo seja manifestado. Porque já o mistério da injustiça opera; somente há um que agora resiste até que do meio seja tirado; e então será revelado o iníquo, a quem o Senhor desfará pelo assopro da sua boca, e aniquilará pelo esplendor da sua vinda; a esse cuja vinda é segundo a eficácia de Satanás, com todo o poder, e sinais e prodígios de mentira $[\ldots]$.

Para Carl Schmitt, o katéchon garantiria a continuidade da existência da República Cristã, atrasando indefinidamente a vinda do Anticristo e, por conseguinte, desacelerando o fim dos tempos e o julgamento final. De modo similar, Schmitt aduz que o estado de exceção poderia ser entendido como um katéchon profano que retardaria o fim do Estado moderno, correspondendo a um obstáculo para a desordem e para o caos apocalíptico-político.

$\mathrm{Na}$ doutrina tradicional, o estado (ou estágio) de exceção se configura como uma provisória suspensão do ordenamento jurídico, pondo-o fora de vigência para manter e preservar da ordem. A exceção permanece até que o soberano decida quando está estabelecida a situação normal de 
segurança e ordem pública para que as normas jurídicas passem a vigorar normalmente. Nesse sentido, “[...] o soberano, que pode decidir sobre o estado de exceção, garante sua ancoragem na ordem jurídica" (AGAMBEN, 2004, p. 56). Assim, pode-se dizer que a decisão soberana, característica da exceção, tem por objetivo a garantia da ordem jurídica, seja preservando ou instaurando o direito.

No entanto, neste texto apresenta-se uma leitura diversa da de Schmitt, tanto no que se refere à sua compreensão da exceção como no que diz respeito ao katéchon. Ao que nos parece, não é a exceção, mas os direitos fundamentais - desde sempre temperados com o princípio da reserva (econômica) do possível - que cumprem o papel de katéchon na tessitura do Estado Democrático de Direito. Mais do que inserir paulatinamente o sujeito nos centros de decisão econômica, eles têm por função mascarar a realidade, entregando aos cidadãos o controle dos centros de decisão política, os quais são inoperantes e absolutamente vazios em uma época impolítica como a que vivemos. Os katéchonta político-jurídicos são então a Constituição e seus direitos fundamentais mantenedores do conflito, seus juízes que transigem e são "razoáveis", que compatibilizam, que num passe de mágica verbal fundamentam, fundamentam e fundamentam, até atingir o nada de uma decisão que existe unicamente para não se aplicar, perdida no tecnicismo e no formalismo de infinitos recursos, reconsiderações, rescisões e prescrições.

O credo do Estado Democrático de Direito (Privado) em que se vive é o da tolerância, do tudo aceitar e de tudo reclamar:

Nunca una época ha estado tan dispuesta a soportarlo todo y a la vez a encontrar todo tan intolerable. Gente que tolera todos los días lo inadmisible tiene sempre a flor de los labios esta palavra cada vez que tiene que dar su opinión sobre un problema cualquiera. (AGAMBEN, 2010, p. 104)

Assim, o lugar do direito democrático-liberal contemporâneo é hoje o da mais extrema desoneração, como se todos nós não fôssemos terrivelmente responsáveis pelas decisões que se tomam, e talvez principalmente por aquelas que não se tomam. Nosso tempo passou a encarar o direito 
enquanto uma máquina fatal, autonomizada e impessoal. Daí a distância entre a força de lei - que gravita em um horizonte negro de irreversibilidade, como as Moiras em busca do sangue de Orestes - e a forma de lei, transformada em mecanismo de autojustificação do poder.

Na nossa época, a violência do poder não se fundamenta em valores últimos a serem realizados, como ocorria no Medievo, mas na simples existência da norma jurídica (forma de lei), conformando um círculo vicioso em que a forma da violência justifica sua própria inevitabilidade, dando lugar a um novo e mais temível - tanto quanto mais falso - naturalismo: o que não consegue pensar fora das estruturas do direito democrático-liberal posto (positivismos de todas as estirpes) ou pressuposto (jusmoralismos de ontem e hoje). Por isso, para fazer face à imensa tarefa do nosso tempo não resta alternativa senão retirar do direito o seu caráter maquinal, desautonomizá-lo à medida que o devolvemos ao reino dos gestos humanos. É claro que isso significa nos responsabilizarmos em pensar um direito que esteja fora do direito ou, o que é o mesmo, uma política.

O direito democrático-liberal é muito parecido com aquele curioso governante russo que, sob a bandeira do "não negociamos com terroristas", fez invadir em outubro de 2002 o Teatro Dubrovska de Moscou, onde um grupo terrorista checheno mantinha mais de mil reféns. Os policiais russos utilizaram um gás paralisante fatal que, além de matar quase todos os terroristas, ceifou a vida de 128 reféns.

Ao não aceitar o diálogo com o radicalmente diferente, o direito democrático-liberal entrega à morte uma parte - que tende continuamente a se agigantar - da comunidade que jurou proteger. As razões disso são muitas, mas talvez a principal delas seja que, ao desconhecer seus inimigos - e, portanto, ao se negar ao desnudamento crítico radical que só o embate pode trazer -, o direito democrático-liberal perpetua mitologemas inoperantes, símbolos desgastados e verdades vazias que servem à dominação da comunidade orquestrada pelos poderes privados que há décadas vicejam sob sua sombra. Refere-se ao poder do dinheiro e da especulação e à "política democrática" que os fundamenta e, de bom grado, garante a contínua passagem da plutonomia à plutocracia. 
Enquanto não se operar uma crítica radical do direito democrático-liberal, será impossível trazer à luz a natureza profundamente antissocial do projeto neoliberal de que ele parte e o qual protege. Ao adiar continuamente a renovação radical e apocalíptica de todas as coisas, ao negar e ao ocultar o caráter construtivo da violência sob as vestes hipócritas dos discursos de inclusão, ao pretender soluções transitivas e negociadas com o poder econômico-especulativo, como se fosse possível peixinhos negociarem com tubarões, conforme alerta um belo texto de Brecht, ${ }^{2}$ o direito democrático-liberal se transforma em um freio, em um mortífero katéchon.

O direito democrático-liberal é, portanto, o que atrasa para sempre, o que adia em direção a um futuro já pretérito a renovação, o que impede o transe final em que o inimigo se torna verdadeiramente irmão e, contrariando Schmitt, realiza o sacrifício final, consentindo em sua própria imolação. No último dia do mundo investiremos contra o econômico, nosso inimigo-irmão, em uma sanha assassina que não conhecerá contemporizações. Pretendendo a destruição, instaura-se o reino messiânico da pura não identidade, que nos libertará da roda das transmigrações, fará cessar o eterno retorno do mesmo, desalojará o princípio da individuação, fará coincidir fé e política, existência e nada. Nestas palavras: fechará a porta da lei.

\section{Walter Benjamin}

Como visto, a única função do katéchon político-jurídico é retardar indefinidamente a justiça, que com fúria golpearia os vendilhões do templo e, no limite, destruiria o próprio templo, colocando em seu lugar um nada; um grande, produtivo e apaixonante vazio. É essa a proposta de Walter Benjamin, que se entrecruza em diferentes níveis e de diversos modos em três de seus textos escritos em momentos muito distantes entre si.

\footnotetext{
2 Trata-se de Se os tubarões fossem homens (Wenn die Haifische Menschen wäre, texto integrante do livro Geschichten von Herrn Keuner), magistralmente interpretado em português por Antônio Abujamra em vídeo disponível no YouTube: <https://www. youtube.com/watch?v=PJnM03vBM_E $>$
} 
O ensaio de juventude intitulado Sobre a Crítica da Violência (Zur Kritik der Gewalt) foi publicado em 1921 sob o influxo da falhada revolução alemã de 1919. Quando Benjamin o escreveu, ele estava impressionado pelos argumentos anarquistas e com a obra de Georges Sorel (Réflexions Sur la Violence, de 1906). Nesse texto, Benjamin começa por caracterizar a violência como meio absoluto do direito, o qual não se importa com fins, mas apenas com a monopolização do meio brutal que sempre o caracterizou. A aparente clareza do artigo vai se perdendo ao longo das páginas que, cada vez mais densas e poéticas, acabam se orientando por uma chave teológico-política muito particular, relacionada não ao catolicismo - como só ocorre na literatura desse tipo (exemplo: Carl Schmitt) -, mas ao messianismo judaico da Cabala.

Ao final do ensaio, Benjamin faz referência àquela tão mal compreendida violência pura (reine Gewalt) ou divina. Tal como o deus do Antigo Testamento, a violência divina não se explica e nem é compreensível, ao contrário da violência mítica, sempre justificadora de si mesma, sempre debatedora e raciocinante, sempre presente enquanto meio absoluto do direito. A violência divina simplesmente golpeia, súbita como um raio. A melhor imagem para ilustrá-la seria a do Messias que, ao contrário do que se poderia esperar de um deus do amor e da humildade, munido de chicote, expulsa os vendilhões do templo, demonstrando o caráter constitucional do ato de violência pura, bem como a possibilidade de assimilar a violência - desde sempre meio de manutenção do sistema - à destruição da estrutura econômica de trocas já estabelecidas no próprio coração do templo e, por isso mesmo, tida não apenas como "normal", mas também inultrapassável.

Para muitos, essa aposta de Benjamin na purgação de todas as coisas por uma violência não dirigida, não justificada e especialmente não estatal, soou como irracionalismo ou imaturidade. Ao contrário, entende-se que tal postura é resultado de uma longa meditação do autor, encontrando eco em vários momentos de sua obra posterior, que alguns intérpretes classificam como "mais madura". Todavia, segundo nos parece, um pensador como Benjamin não pode ser recortado em vários pedaços, devendo antes ser compreendido na unidade contraditória de sua vida e obra. 
Em 1931, Benjamin publica na revista literária Literaturblatt der Frankfurter Zeitung o devastador microtexto O Caráter Destrutivo (Der Destruktive Charakter), no qual alguns temas apenas evocados no ensaio de 1921 são retomados de forma ainda mais agressiva e condensada, conformando um projeto de destruição que somente pode ser entendido em conexão com as Teses de 1940, que serão comentadas em seguida.

No pequeno texto de 1931, que para alguns intérpretes teria sido escrito por Benjamin quando ele toma seriamente e pela primeira vez a decisão de suicidar-se, algo que iria se concretizar (?) apenas em 1940, desponta uma espécie de vontade-de-destruição necessária à transformação messiânica por não estar comprometida com qualquer ânimo reformista ou projeto predeterminado. Assim como a violência pura não tem um sinal ou direção fixa, o caráter destrutivo abre mão de justificativas e planos, sob pena de, os adotando, se inserir no mecanismo da violência mítica que serve ao direito, sendo sempre legitimada por suas pretensões aparentemente universalistas e "humanitárias". Ao contrário, ao caráter destrutivo importa destruir,

[...] pois destruir rejuvenesce, porque afasta as marcas de nossa própria idade; reanima, pois toda eliminação significa, para o destruidor, uma completa redução, a extração da raiz de sua própria condição. O que leva a esta imagem apolínea do destruidor é, antes de mais nada, o reconhecimento de que o mundo se simplifica terrivelmente quando se testa o quanto ele merece ser destruído. [...] O caráter destrutivo não vê nada de duradouro. Mas, por isso mesmo, vê caminhos por toda a parte. Mesmo onde os demais esbarram em muros ou montanhas, ele vê um caminho. Mas porque vê caminhos por toda a parte, também tem que abrir caminhos por toda a parte. Nem sempre com força brutal, às vezes, com força refinada. Como vê caminhos por toda a parte, ele próprio se encontra sempre numa encruzilhada. Nenhum momento pode saber o que trará o próximo. Transforma o existente em ruínas, não pelas ruínas em si, mas pelo caminho que passa através delas. (BENJAMIN, 1986, p. 187-188)

Bem se vê que a destruição, apesar de cega, não é sem objetivo. Ela pretende abrir espaço, pois vê caminhos por toda parte. Mas que espaços 
são esses? A resposta só viria em 1940, no último e mais grandioso texto de Walter Benjamin, as Teses Sobre o Conceito de História (Über den Begriff der Geschichte), escrito pouco antes de sua morte em Portbou, vilarejo catalão da Espanha no qual o autor se encontrava para tentar cruzar a fronteira francesa e escapar dos nazistas. Saber se Benjamin se matou (voluntária ou involuntariamente, mediante a ingestão de uma dose exagerada de morfina) ou se foi morto (pelos franquistas, pelos nazistas ou, na mais interessante versão, pelos stalinistas) é até hoje uma questão apaixonante e sem resposta unívoca ${ }^{3}$.

Nas Teses, Benjamin nos alerta sobre a impossibilidade de se negociar com o tempo e as instituições capitalistas, que devem ser negadas em bloco e sem quaisquer tergiversações. Só assim a catástrofe pode ser não detida - como no katéchon schmittiano, mecanismo de desaceleração do fim dos tempos -, mas definitivamente aniquilada pelo tempo-de-agora (Jetztzeit). Trata-se de fundar um novo agora messiânico-utópico profundamente comprometido com o tempo e suas descontinuidades, constantemente falseadas e "reconstruídas" pelos idealismos das várias filosofias da história, entre as quais o capitalismo representa apenas a versão mais conhecida.

Todo presente é um impedimento ao futuro absoluto, que não depende de condições atuais e se põe como verdadeira exceção diante do contínuo da história, como explicitado na Tese VIII. De acordo com Benjamin, há uma imobilidade estrutural que perpassa as lutas de classe, razão pela qual os escravos jamais venceram os cidadãos livres na Antiguidade e os servos sempre foram subjugados pela nobreza no Medievo, sendo a burguesia a única classe revolucionária que sempre venceu. Isso traz como consequência o fato de se viver sob um estado de exceção que é a regra, urgindo substituí-lo por um real estado de exceção. É a enunciação da Tese VIII:

A tradição dos oprimidos ensina-nos que o "estado de exceção" ['Ausnahmezustand'] em que vivemos é a regra. Temos de chegar

${ }^{3}$ Para uma narrativa objetiva e detalhada da morte de Benjamin, cf. Tackels (2012, p. 501-520). 
a um conceito de história que corresponda a essa ideia. Só então se perfilará diante dos nossos olhos, como nossa tarefa, a necessidade de provocar o verdadeiro estado de exceção [wirklichen Ausnahmezustands]; e assim a nossa posição contra o fascismo melhorará. A hipótese de ele se afirmar reside em grande parte no fato de os seus opositores o verem como uma norma histórica, em nome do progresso. O espanto por as coisas que assistimos "ainda" poderem ser assim no século vinte não é um espanto filosófico. Ele não está no início de um processo de conhecimento, a não ser o de que a ideia de história de onde provém não é sustentável. (BENJAMIN, 2012, p. 13)

Ao longo da história do Ocidente, a regra vem sendo a dominação e a barbárie, travestida ou não sob as formas democráticas. Um verdadeiro estado de exceção (wirklicher Ausnahmezustand) é então aquele que representa uma exceção real nesse continuum histórico marcado pela permanência da submissão da maioria diante da força da minoria. Trata-se de conferir à exceção seu significado primigênio de revirada, corte e absoluta exterioridade em relação ao que está dado e regrado.

Ao contrário de Schmitt, para Benjamin, o verdadeiro estado de exceção não se revela como estrutura estatal em que o direito está suspenso e, por isso, se autorizam as maiores atrocidades para mantê-lo (ditadura comissária) ou refundá-lo (ditadura soberana). Diferentemente, o verdadeiro estado de exceção - que, segundo a Tese VIII, tornará melhor a nossa luta contra o fascismo - corresponde a um signo de descontinuidade diante da história político-jurídica do Ocidente, representando não um desacelerador do tempo, mas um verdadeiro redirecionador da história.

Nessa concepção, a exceção não significa suspensão do direito, mas seu desvio. Por isso, mais do que verdadeiramente exceptiva - no sentido schmittiano de algo que suspende a normatividade comum para refundá-la -, a verdadeira exceção que Benjamin visualiza é excessiva. Para dar conta de tal exigência, o pensar filosófico precisa assumir aquelas características que Nietzsche ligara ao seu conceito intempestivo de história, que se põe "[...] contra o tempo, para agir sobre o tempo e favorecer o acontecimento de um tempo futuro." (NIETZSCHE, 1982, p. 5). 
Assim, se é certo que o poder absoluto - normalmente oculto pelos mecanismos de mediação, característicos da representação democrático-parlamentar - só se mostra quando age diretamente diante do caso de exceção, é preciso realizar a verdadeira exceção de que fala Benjamin na Tese VIII, fazendo aflorar, além de todas as retóricas democrático-liberais, a democracia radical da multidão, capaz de fazer o poder, que não é algo diverso do desejo de igualdade, agir diretamente sobre o mundo.

\section{Gotham City}

Os dois últimos filmes da trilogia Batman dirigida por Christopher Nolan são significativos, descontados, por óbvio, os clichês e as finalizações sem as quais o produto seria invendável. No terceiro e último filme da série, o herói enfrenta Bane, que não é propriamente um vilão. Assim como o Coringa do segundo filme, Bane não tem objetivos muito claros. Ambos parecem ser meios sem fim, para adotar a linguagem de Giorgio Agamben, inspirada por Benjamin.

O Coringa e Bane são representantes da violência pura que nada pretende, senão abrir espaço, abrir cada vez mais e maiores espaços. Em especial, a figura do Coringa reproduz ponto por ponto o retrato do caráter destrutivo delineado por Benjamin: onde outros veem muros, ele vê caminhos. É paradigmática a cena em que o Coringa ateia fogo a uma pilha de dinheiro, deixando perplexos seus comparsas. Ele encarna em si uma verdadeira complexio oppositorum, ininteligível para a mente criminosa comum que, assim como a racionalidade econômica, só consegue pensar maquinalmente. "Não é isso que eu quero - parece dizer o terrível palhaço -, na verdade, eu não quero nada; nada mesmo!" E é impossível que o espectador não ame profundamente essa potência negativa que cria o caos, animado talvez pela mesma subjetividade sem finalidade que levou Deus a criar o mundo.

Há nos dois últimos filmes da trilogia um discurso subliminar que questiona a ordem, afinal mantida por uma figura exterior - o Batman que a ela não se submete, postando-se diante da realidade de Gotham City como o soberano schmittiano que, criador da ordem a partir da exceção, 
paradoxalmente não pode impedir que essa mesma ordem engendre, por meio de específicas ordenações, novas e mais profundas deslocalizações.

Essa situação chega ao máximo paroxismo no terceiro filme, quando uma Gotham City sob lei marcial, pacificada com base nas mentiras fundadoras patrocinadas pelos agentes da ordem - o Batman e seu indefectível colaborador, o comissário Gordon -, se vê diante da violência pura de um verdadeiro estado de exceção, muito similar àquele pensado por Benjamin. Sob a autoridade do Batman, a cidade vivia até então um estado de sítio fictício, nos dois sentidos do termo: 1) o crítico-benjaminiano, aludido no começo da Tese VIII, caracterizando-se por não levar às últimas consequências os seus pressupostos, quer dizer, não se tornar um verdadeiro estado de exceção (wirklicher Ausnahmezustand) que se oponha à barbárie que sempre foi a regra na história, conforme lida pela tradição dos oprimidos; 2) o francês tradicional, segundo o qual o état de siège designa um estado que, não sendo de guerra, opera ficcionalmente como se o conflito bélico fosse o único referencial estratégico a se considerar.

Desse modo, se, com o Batman, a cidade vivia sob um estado de sítio fictício, com Bane, ela experimentará a violência pura característica do verdadeiro estado de exceção. Depois de aleijar Bruce Wayne e exilá-lo na infernal prisão em que ele próprio cresceu - aparentemente localizada em algum buraco do Oriente Médio, o que não deixa de ser significativo -, Bane subverte a ordem de Gotham. Ele revela as mentiras sob as quais a lei e o direito eram mantidos, inverte as relações sociais e liberta presos condenados, transformando-os em juízes de magnatas, políticos e empresários. Em uma palavra, Bane entrega a cidade aos seus cidadãos. Ao mesmo tempo, ele a mantém isolada do mundo externo, criando um interessante experimento socioantropológico.

Na Gotham de Bane, o povo presta contas apenas a si mesmo; e o que era privado passa a ser comum, como em uma cena na qual a lânguida Mulher-Gato, presa de uma breve crise de consciência pequeno-burguesa, se lamenta diante dos escombros de uma outrora luxuosa residência: "aqui já foi a casa de alguém", recebendo de imediato a resposta de sua amiga: "agora é a casa de todos". 
A pedra de toque da estrutura exceptiva ideada por Bane reside no fato de ser um experimento isolado, posto a salvo de influências tanto externas quanto internas. Com efeito, Bane consegue prender nos túneis do esgoto toda a polícia de Gotham City e, de posse de uma bomba termonuclear, ameaça destruir a cidade caso as autoridades federais exteriores interfiram em seu laboratório antropológico. Mais ainda: ele exige que o exército americano colabore com seu plano e impeça os cidadãos de Gotham de abandoná-la, sob pena de acionamento da bomba que explodirá a cidade inteira. Assim, as fronteiras de Gotham passam a ser vigiadas por tropas federais que impedem o êxodo de alguns de seus desesperados cidadãos. Com isso, Bane demonstra que a força que protege é a mesma que oprime; ou melhor, que para proteger - evitar a detonação da bomba - é necessário oprimir - impedir que os cidadãos abandonem o inferno que se tornou Gotham City, condenando-os ao caos.

A partir desse momento, o telespectador começa a ficar preocupado e o filme parece se encaminhar para um final dificilmente digerível pelas plateias que foram ao cinema apenas querendo ver mais uma fábula moral. É óbvio, contudo, que as coisas se ajeitam. Dono de uma força de vontade sobrenatural, o Batman consegue, refazendo os passos de seu inimigo e se tornando tão forte quanto ele - as ressonâncias schmittianas são bem claras aqui -, escapar do buraco em que estava exilado, algo que aparentemente só Bane até então tinha feito. Ele então volta à sua cidade e vence o vilão, secundado por honrados policiais e pela deliciosa Mulher-Gato, com quem Bruce Wayne acaba no final em um idílico café florentino.

Na verdade, essa conclusão banal importaria muito pouco se o diretor já não tivesse estragado sua trama, genial até certo momento. É que Bane estava determinado de antemão a detonar a bomba atômica em certo dia e horário, independentemente do que fizessem os cidadãos de Gotham durante o período da "experiência". Por mais que as relações sociais se modificassem, o destino da cidade já estava selado a partir da decisão de uma autoridade absoluta, que tomou o lugar dos anteriores soberanos apenas para se tornar igual a eles. $\mathrm{O}$ interessante, o inimaginável para $\mathrm{o}$ público seria se Nolan tivesse efetivamente completado a fábula transvalorativa que ele apenas insinuou: se Bane tivesse matado o Batman - 
escapando assim do joguinho de amigo e inimigo que define o soberano do estado de exceção - ao invés de deixá-lo vivo para que, milagrosa e previsivelmente, ressurgisse. Se Bane instaurasse seu experimento sem a obsessão infantil de destruí-lo, se o deixasse fluir de modo indefinido, então... então o quê? É exatamente em uma situação assim que poderia surgir a violência pura e, com ela - mas nunca devido a ela -, o direito que vem.

\section{Conclusão}

Mediante a profanação, Agamben pretende conferir um novo caráter ao direito, desativando-o e entregando-o ao uso comum, retirando-o desse modo da esfera do sagrado ao qual foi abandonado desde a sua origem. Mas não é isso - desativar o direito - o que a violência pura da verdadeira exceção faz? Talvez seja necessário dar razão a Benjamin, que via na verdadeira exceção a única via de saída para o direito mítico-violento. Ao desativá-lo, a exceção consagra-o a um não uso, a uma radical imediação, a uma $a$-instrumentalidade. Mas para que serve um direito assim? Para nada. Ele já não serve para nada e a ninguém. Daí sua impossibilidade, que não deixa de ser divina. O direito desativado não é, contudo, projeto ou ideal regulativo, mas signo e símbolo, quem sabe destino de uma nova comunidade: sem mediação do econômico-parlamentar, entregue a si mesma.

\section{Referências}

AGAMBEN, Giorgio. Elogio da profanação. In: AGAMBEN, Giorgio.

Profanações. Trad. e apresentação de Selvino J. Assmann. São Paulo: Boitempo, 2007. p. 58-72.

AGAMBEN, Giorgio. Estado de exceção. Trad. Iraci D. Poleti. São Paulo: Boitempo, 2004.

AGAMBEN, Giorgio. Medios sin fin: notas sobre la politica. Trad. Antonio Gimeno Cuspinera. Madrid: Pre-Textos, 2010. 
BENJAMIN, Walter. O caráter destrutivo. In: BENJAMIN, Walter. Documentos de cultura, documentos de barbárie: escritos escolhidos. Seleção e apresentação Willi Bolle. Trad. Celeste H. M. Ribeiro de Sousa et al. São Paulo: Cultrix/Universidade de São Paulo, 1986. p. 187-188. BENJAMIN, Walter. Para uma crítica da violência. In: BENJAMIN, Walter. Escritos sobre mito e linguagem (1915-1921). Organização, apresentação e notas de Jeanne Marie Gagnebin. Trad. Susana Kampff Lages e Ernani Chaves. São Paulo: Duas Cidades/Editora 34, 2011. p. 121-156.

BENJAMIN, Walter. Sobre o conceito da história. In: BENJAMIN, Walter. O anjo da história. Trad. João Barrento. Belo Horizonte: Autêntica, 2012.

BRECHT, Bertolt. Histórias do sr. Keuner. Trad. Paulo César de Souza. São Paulo: Editora 34, 2013.

NIETZSCHE, Friedrich Wilhelm. Zweites Stück: vom Nutzen und Nachteil der Historie für das Leben. Stuttgart: Reclam, 1982.

NOLAN, Christopher (director). Batman begins. EUA/United Kingdom: DC Comics; Legendary Pictures; Syncopy Films; Patalex Production III. Color, 141 min., 2005.

NOLAN, Christopher (director). The dark knight. EUA/United Kingdom: DC Comics; Legendary Pictures; Syncopy Films. Color, 152 $\min ., 2008$.

NOLAN, Christopher (director). The dark knight rises. EUA/United Kingdom: DC Comics; Legendary Pictures; Syncopy Films. Color, 165 min., 2012.

SOREL, Georges. Reflexões sobre a violência. Trad. Paulo Neves. São Paulo: Martins Fontes, 1992.

TACKELS, Bruno. Walter Benjamin: una vida en los textos. Trad. Josep Aguado Codes e Inmaculada Miñana Arnao. València: Universitat de València, 2012. 
Andityas Soares de Moura Costa Matos é graduado em Direito, mestre em Filosofia do Direito e doutor em Direito e Justiça pela Faculdade de Direito e Ciências do Estado da Universidade Federal de Minas Gerais (UFMG), doutorando em Filosofia pela Universidade de Coimbra (Portugal), professor adjunto de Filosofia do Direito e disciplinas afins na Faculdade de Direito e Ciências do Estado da UFMG, membro do corpo permanente do Programa de Pós-Graduação em Direito da Faculdade de Direito e Ciências do Estado da UFMG, professor visitante na Facultat de Dret de la Universitat de Barcelona (Catalunya) entre 2015 e 2016 e autor de ensaios jusfilosóficos como Filosofia do Direito e Justiça na Obra de Hans Kelsen (Belo Horizonte, Del Rey, 2006), O Estoicismo Imperial como Momento da Ideia de Justiça: Universalismo, Liberdade e Igualdade no Discurso da Stoá em Roma (Rio de Janeiro, Lumen Juris, 2009), Kelsen Contra o Estado (em: Contra o Absoluto: Perspectivas Críticas, Políticas e Filosóficas da Obra de Hans Kelsen, Curitiba, Juruá, 2012), Contra Naturam: Hans Kelsen e a Tradição Crítica do Positivismo jurídico (Curitiba, Juruá, 2013), Power, Law and Violence: Critical Essays on Hans Kelsen and Carl Schmitt (Lambert, Saarbrücken [Alemanha], 2013), O Grande Sistema do Mundo: do Pensamento Grego Originário à Mecânica Quântica (Belo Horizonte, Fino Traço, 2014) e Filosofia Radical e Utopias da Inapropriabilidade: Uma Aposta An-árquica na Multidão (Belo Horizonte, Fino Traço, 2015).

E-mail: vergiliopublius@hotmail.com e andityas@ufmg.br

Endereço profissional: Faculdade de Direito da Universidade Federal de Minas Gerais - Av. João Pinheiro n. 100 - Bairro Centro - Belo Horizonte/MG - 30130180 - Brasil. 
